\title{
Is the use of e-cigarettes for smoking cessation associated with alcohol consumption? A population-level survey of successful quitters in England
}

\author{
Sarah E. Jackson ${ }^{1}$, Emma Beard ${ }^{1}$, Susan Michie ${ }^{2}$, Robert West ${ }^{1}$, Jamie Brown ${ }^{1,2}$ \\ ${ }^{1}$ Department of Behavioural Science and Health, University College London, London, UK \\ ${ }^{2}$ Department of Clinical, Educational and Health Psychology, University College London, UK
}

Corresponding author: Dr Sarah Jackson, Department of Behavioural Science and Health, University College London, 1-19 Torrington Place, London WC1E 7HB, UK. s.e.jackson@ucl.ac.uk +44 (0)207 6798312 


\section{Abstract}

Objective: To examine associations between the use of e-cigarettes for smoking cessation and levels of alcohol consumption, high-risk drinking, and attempts to cut down alcohol consumption compared with use of nicotine replacement therapy (NRT) or no aid.

Methods: Cross-sectional survey of adults ( $\geq 16$ years) in England. The sample included 961 people who had quit smoking with the use of e-cigarettes $(n=425)$, NRT $(n=116)$, or no aid $(n=421)$ within the past year and were still abstinent at the survey. Drinking behaviour was assessed with the AUDIT.

Results: Mean(SD) alcohol consumption among those who quit smoking with e-cigarettes, NRT, and no aid was 7.78(13.41), 7.12(13.85), and 5.55(8.70) units/week, respectively. The prevalence of high-risk drinking was $43.3 \%(n=184), 32.2 \%(n=37)$, and $36.8 \%(n=155)$, respectively. Among high-risk drinkers, the prevalence of attempts to cut down alcohol consumption was $22.3 \%(n=41), 18.9 \%(n=7)$, and $27.7 \%(n=43)$, respectively. After adjustment for covariates, those who quit with e-cigarettes had significantly higher alcohol consumption than those who quit unaided ( $B=1.69,95 \% \mathrm{Cl} 0.21-3.17)$, but there was no significant difference relative to those who quit with NRT. Differences in high-risk drinking and attempts to cut down were not significant, but Bayes factors indicated the data were insensitive (range:0.47-0.95).

Conclusions: Recent ex-smokers who used e-cigarettes to help them quit consumed around two more units of alcohol each week than those who quit unaided, but their alcohol consumption was similar to those who quit with NRT. Data on differences in high-risk drinking and attempts to cut down alcohol consumption among high-risk drinkers were inconclusive.

Key words: e-cigarettes; vaping; alcohol; drinking; smoking cessation 


\section{Introduction}

Smoking and high-risk alcohol consumption are among the leading causes of morbidity and mortality worldwide (Griswold et al., 2018; Reitsma et al., 2017). Numerous studies have established a strong relationship between smoking and alcohol use (Grant et al., 2004; McKee et al., 2007; Noble et al., 2015). Individuals who drink alcohol at high-risk levels (i.e. levels that are harmful to health, defined by an Alcohol Use Disorders Identification Test (AUDIT) score of 8 or higher (Babor et al., 2001)) are substantially more likely to smoke (Falk et al., 2006; Kalman et al., 2005; Kessler et al., 2005; Lasser et al., 2000). Smokers who smoke more heavily tend to have higher levels of alcohol consumption (Friedman et al., 1991; Kaner et al., 2007), and those who attempt to quit typically reduce their alcohol intake at the same time (Brown et al., 2016). At a population level, changes in smoking prevalence have been shown to correlate positively with changes in the prevalence of high-risk drinking (Beard et al., 2017). Encouraging smoking cessation may therefore have dual benefits for both smoking and alcohol consumption. This study explores the extent to which use of e-cigarettes in a quit attempt - an increasingly popular aid (Filippidis et al., 2017; McMillen et al., 2015; West et al., 2019) - is associated with alcohol consumption and attempts to reduce alcohol consumption.

Following a period of rapid growth in prevalence of use from 2011 to 2014, e-cigarettes (also known as electronic cigarettes, electronic nicotine delivery systems, or vapes) are currently the most popular smoking cessation aid in England: they are used by around 2.6 million people ( $20 \%$ of smokers) and are used in over one third of quit attempts (West et al., 2017). However, several studies have found that e-cigarette users tend to have higher levels of alcohol consumption and are more likely to binge drink (Hershberger et al., 2016c, 2016b; Saddleson et al., 2015). Moreover, prohibiting e-cigarette use in places where people consume alcohol has been shown to be associated with lower alcohol consumption (Hershberger et al., 2016a).

These findings are seemingly at odds with evidence of associations between e-cigarette use and increased quit rates (Hartmann-Boyce et al., 2018, 2016), and quitting smoking and lower alcohol consumption (Brown et al., 2016). However, a couple of methodological issues limit interpretation of these results. First, the unrepresentativeness of sample recruitment procedures limits generalisation of results to the whole smoker population. For example, one study (Saddleson et al., 2015) focused on college students, a population known for particularly high rates of alcohol use (O'Malley and Johnston, 2002). Secondly, none of these studies focused specifically on e-cigarette use in a quit attempt. People use e-cigarettes for 
different reasons; most commonly as a smoking cessation tool, but also as a nicotine replacement product (e.g., in situations where smoking is not permitted) (Biener and Hargraves, 2015; McNeill et al., 2018; Patel et al., 2016; Rutten et al., 2015; Simonavicius et al., 2017). Data from the US indicate that e-cigarettes are used by more than one in ten $10 \%$ of smokers who are not trying to quit have not made a quit attempt in the past year use e-cigarettes-(Schoenborn and Gindi, 2015). Inclusion of smokers who are not trying to quit in analyses likely influences the observed relationship between e-cigarette use and alcohol consumption.

Evidence that e-cigarette use is associated with increased alcohol consumption contrasts with evidence on use of other smoking cessation aids, such as nicotine replacement therapy (NRT), which have been found to be associated with reduced alcohol consumption in heavy-drinking smokers (Acheson et al., 2006; McKee et al., 2008; Young et al., 2005) and attenuated alcohol response and craving (Udo et al., 2013). It is possible that differences in associations between e-cigarettes and NRT may be due to the greater similarity of ecigarettes to cigarettes in their behavioural action (McNeill et al., 2018) preventing the uncoupling of conditioned stimulus-response effects between smoking and alcohol (Rohsenow et al., 1997). However, the disparate results could also be accounted for by methodological differences (e.g., unmeasured confounding in the types of people who use the different aids or in sample populations, as discussed above). NRT use in a quit attempt provides a useful real-world behavioural control for e-cigarette use in a quit attempt because it reduces the risk of confounding, for example by the comparatively higher levels of nicotine dependence and motivation to quit among smokers who use cessation aids (Shi et al., 2016).

Evaluation of the association between use of e-cigarettes for smoking cessation and alcohol consumption is important for informing policy and clinical practice. Although e-cigarettes have been shown to promote attempts to stop smoking in three clinical trials (Hajek et al., 2019; Hartmann-Boyce et al., 2016) and population-level surveys (Beard et al., 2016), the impact on public health would be mitigated if they were associated with increased alcohol use. Such a finding would highlight the need for further research to determine whether targeted behavioural support and other measures to reduce alcohol consumption for this group were warranted for smokers attempting to quit with e-cigarettes.

This study examined the association between the use of e-cigarettes for smoking cessation and level of alcohol consumption using data from a representative population survey of adults in England. Associations between a recent successful attempt to quit smoking using e-cigarettes and (i) alcohol consumption, (ii) high-risk drinking, and (iii) attempts to reduce alcohol consumption were assessed. Comparator groups were smokers who made a successful attempt to quit using NRT or no aid. 
Specifically, we aimed to address the following research questions:

1. Among past-year smokers, is the use of e-cigarettes for smoking cessation associated with (i) lower alcohol consumption or (ii) lower prevalence of high-risk drinking relative to use of NRT or no aid, adjusting for relevant sociodemographic and smoking characteristics, injury to self or others from drinking, and concern about drinking expressed by others (a proxy for longer-term high-risk drinking)?

2. Among high-risk drinkers, is the use of e-cigarettes for smoking cessation associated with attempts to reduce alcohol consumption relative to use of NRT or no aid, adjusting for relevant sociodemographic characteristics, injury to self or others from drinking, and concern about drinking expressed by others?

\section{Materials and methods}

\subsection{Design and procedures}

Data were drawn from the ongoing Smoking and Alcohol Toolkit Studies, monthly cross-sectional surveys of a representative sample of adults ( $\geq 16$ years) in England designed to provide tracking information about smoking, alcohol consumption and related behaviours in England (Beard et al., 2015; Fidler et al., 2011a). Each month a new sample of approximately 1,700 participants complete face-to-face computer-assisted interviews. The sampling is a hybrid between random probability and simple quota and the method has been shown to result in a sample that is nationally representative in its sociodemographic composition (Fidler et al., 2011b). The present analyses used pooled data from consecutive monthly waves between March 2014 (the first wave to include assessment of alcohol consumption) and February 2019 (the most recent wave for which data were available at the time of analysis).

Ethical approval for the STS was granted by the UCL Ethics Committee (ID 0498/001). The data are not collected by UCL and are anonymised when received by UCL.

\subsection{Sample}

We included respondents who: (i) reported smoking cigarettes (including hand-rolled) or other forms of tobacco (e.g. pipe or cigar) in the last year; (ii) had made at least one serious attempt to stop smoking in the 
last year; (iii) were still not smoking at the time of the survey; and (iv) reported using e-cigarettes, NRT, or no aid during their most recent quit attempt. Our rationale for restricting our sample to successful quitters was that people tend to drink less while still abstinent and including failed quitters would introduce confounding by treatment success. We made no exclusions on the basis of extent of alcohol use.

\subsection{Measures}

\subsubsection{Smoking status and cessation}

Smoking status was assessed with the question: "Which of the following best applies to you? (i) I smoke cigarettes (including hand-rolled) every day; (ii) I smoke cigarettes (including hand-rolled), but not every day; (iii) I do not smoke cigarettes at all, but I do smoke tobacco of some kind (e.g. pipe, cigar or shisha); (iv) I have stopped smoking completely in the last year; (v) I stopped smoking completely more than a year ago; (vi) I have never been a smoker (i.e. smoked for a year or more)."

Quit attempts among past-year smokers were assessed with the question: "How many serious attempts to stop smoking have you made in the last 12 months? By serious attempt I mean you decided that you would try to make sure you never smoked again. Please include any attempt that you are currently making, and please include any successful attempt within the last 12 months."

\subsubsection{Exposure}

The independent variable was use of e-cigarettes, NRT obtained over-the-counter, or no aid (defined as no use of e-cigarettes, NRT (obtained over-the-counter or on prescription), prescription medication and/or behavioural support) during the most recent quit attempt, assessed with the question "Which, if any, of the following did you try to help you stop smoking during the most recent serious quit attempt?". Any types of NRT was included, although the wording of the response option for NRT obtained over-the-counter specifically mentioned patches, gum and inhalers as examples. Participants who reported using prescription medication (varenicline, bupropion, or NRT) or behavioural support were excluded from the analyses because they may have been more likely to receive advice on reducing alcohol consumption.

\subsubsection{Outcomes}


Outcome variables were alcohol consumption, high-risk drinking, and current attempts to cut down alcohol consumption. Participants completed the AUDIT (Babor et al., 2001), a 10-item screening tool developed by the World Health Organization.

An estimate of mean weekly unit consumption (one unit of alcohol is defined as 10 millilitres (8 grams) of pure alcohol and is a commonly used measure in the UK) was derived from the first two questions of the AUDIT which assess the quantity and frequency of alcohol consumption (AUDIT-QF). Extended response options were used to allow more granular responses at the highest level of consumption: 1) How often do you have a drink containing alcohol? (never, monthly or less, 2-4 times a month, 2-3 times a week, 4-5 times a week, 6 or more times a week), and 2) How many drinks containing alcohol do you have on a typical day when you are drinking? (1-2, 3-4, 5-6, 7-9, 10-12, 13-15, 16 or more). Mean weekly unit consumption was calculated by multiplying number of drinks by weekly frequency using the midpoint of the range in the response options, e.g. 4-5 drinking occasions per week was scored 4.5. This derived weekly unit consumption measure has been used previously (Beard et al., 2019; Lima et al., 2005).

High-risk drinking was measured with the first three questions of the AUDIT (AUDIT-C), which assess the quantity and frequency of alcohol consumption (questions 1 and 2 above) and binge drinking: 3) How often do you have six or more drinks on one occasion? (never, less than monthly, monthly, weekly, daily or almost daily). High-risk consumption will be defined as an AUDIT-C score $\geq 5$ (Bradley et al., 2007)).

High-risk drinkers were asked whether they were currently attempting to restrict their alcohol consumption: "Are you currently trying to restrict your alcohol consumption, e.g. by drinking less, choosing lower strength alcohol or using smaller glasses? (yes/no)".

\subsubsection{Covariates}

Sociodemographic covariates included: age, sex, ethnicity (white vs. non-white), social grade (ABC1, which includes managerial, professional and intermediate occupations, vs. C2DE, which includes small employers and own-account workers, lower supervisory, and technical occupations, and semi-routine and routine occupations, never worked, and long-term unemployed), government office region in England (dichotomised to North, which includes North East, North West, and Yorkshire and the Humber, East Midlands, West Midlands, or South, which includes East of England, London, South East, and South West; classified according to an established North-South divide (Hacking et al., 2011)), and education (post-16 qualifications, yes/no). These variables have previously been shown to be associated with use of e- 
cigarettes and drinking behaviour (Brown et al., 2014; Caetano et al., 2011; Levy et al., 2017; Vardavas et al., 2015).

Smoking characteristics included: time since quit, and strength of urges to smoke (an indicator of cigarette addiction). These variables were controlled for because we thought it likely that more recent quitters or those who were more addicted may be more likely to avoid alcohol in order to minimise the risk of relapse. We also included current use of e-cigarettes and current use of NRT at the time of the survey, as we expected smokers who quit using e-cigarettes to be more likely to still be using them after cessation than those who quit using NRT were to still be using NRT (Hajek et al., 2019; Jackson et al., 2019).

Drinking characteristics included: injury to self or others from drinking, and concern about drinking or advice to cut down from a relative/friend/health professional (each coded 0 for no, 2 for yes but not in the last year, and 4 for yes during the last year) (Babor et al., 2001). Because this study was cross-sectional and did not include data on usual alcohol consumption prior to quitting smoking, it is possible that selection of ecigarettes versus NRT or no aid differed by prior alcohol use, introducing potential for unmeasured confounding. These two variables were included to account to some extent for longer-term drinking habits, addressing problems related to the cross-sectional study design.

\subsection{Statistical analysis}

The analysis plan was pre-registered on Open Science Framework (https://osf.io/zarvs/). Analyses were done on complete cases in SPSS v.24.

We used Pearson's chi-square tests (categorical variables) and one-way independent analysis of variance (continuous variables) to analyse differences in covariates across those who recently quit smoking with ecigarettes, NRT, and no aid.

For our primary analyses, we first constructed unadjusted regression models in which recent attempts to quit smoking with either e-cigarettes, NRT, or no aid were regressed onto (i) alcohol consumption, (ii) highrisk drinking, and (iii) attempts to reduce alcohol consumption. Linear regression was used for the continuous dependent variable (mean weekly alcohol consumption) and logistic regression models for the binary dependent variables (proportion classified as high-risk drinkers, and attempting to reduce alcohol consumption). We then constructed multivariable regression models also including age, sex, ethnicity, social 
grade, region, education, time since quit, strength of urges to smoke, injury to self or others from drinking, concern about drinking expressed by others, and the survey year (entered as a continuous variable).

We performed three-four sensitivity analyses. The first excluded non-drinkers to evaluate the extent to which this affects the results. The second excluded those in the e-cigarette and NRT groups who reported having received behavioural support for their quit attempt, because this might have included advice to reduce alcohol consumption. The third (unplanned) sensitivity analysis adjusted for current use of ecigarettes and NRT at the time of the survey. The fourth (unplanned) sensitivity analysis tested for sex differences in associations by adding an interaction term between cessation aid used (e-cigarettes, NRT, no aid) and sex into the multivariable models.

To aid interpretation of the results, we calculated Bayes factors (BFs) for our primary adjusted model results to differentiate between evidence for the alternative hypothesis (i.e. higher alcohol consumption, higher prevalence of high-risk drinking, and lower prevalence of attempts to cut down alcohol consumption among those who quit smoking with e-cigarettes), evidence for the null hypothesis, and data insensitivity. BFs were calculated using an online calculator

(http://www.lifesci.sussex.ac.uk/home/Zoltan_Dienes/inference/Bayes.htm), with alternative hypotheses represented by a half-normal distribution and the absolute expected effect size set to $B=3$ for alcohol consumption and the equivalent of $\mathrm{OR}=2$ in the expected direction for categorical outcomes ( $O R=2$ for highrisk drinking, $\mathrm{OR}=0.5$ for attempts to cut down alcohol consumption). Our expected effect sizes were based on what we believed would be a meaningful difference in drinking behaviour (Kaner et al., 2007). BFs $\geq 3$ can be interpreted as evidence for the alternative hypothesis (and against the null), $B F s \leq 1 / 3$ as evidence for the null hypothesis, and BFs between $1 / 3$ and 3 suggest the data are insensitive to distinguish the alternative hypothesis from the null (Dienes, 2014; Jeffreys, 1961).

\section{Results}

A total of 101,819 people responded to the survey between March 2014 and February 2019, of whom $19,734(19.4 \%)$ reported smoking in the past year. Of past-year smokers, 6,137 (31.1\%) reported having made a serious attempt to quit in the past year, and 1,048 (17.1\%) of these were still abstinent at the time of the survey. Of this sample of successful quitters, 429 (40.9\%) had used an e-cigarette in their most recent quit attempt, 116 (11.1\%) had used NRT obtained over-the-counter, and 425 (40.6\%) had used no aid. The 
remaining $78(7.4 \%)$ reported using prescription medication or behavioural support and were excluded from our analytic sample. We also excluded 9 participants with missing data on alcohol consumption, leaving a final sample of 961 men and women. For comparative purposes, Table S1 provides descriptive data on our outcomes of interest for (i) all current smokers, (ii) current smokers who made a serious quit attempt in the past year (i.e. failed quitters), (iii) current dual users of tobacco and (a) e-cigarettes and (b) NRT, and (iv) those who quit smoking successfully using (a) prescription medication and (b) behavioural support.

Sample characteristics in relation to quitting aid are summarised in Table 1. The age profile of quitters differed by quitting aid. In addition, those who had quit smoking with e-cigarettes were significantly more likely to be male and white than those who quit with NRT or no aid. Those who had quit with NRT reported the strongest urges to smoke, and those who had quit with no aid the weakest. Nine in ten participants who quit smoking with e-cigarettes were still using e-cigarettes at the time of the survey, and two-thirds of participants who quit with NRT were still using NRT. There were no significant differences in social grade, region, education, time since quit, injury to self or others from drinking, concern about drinking expressed by others, or survey year.

Associations between quitting aid and drinking behaviour are summarised in Table 2. Mean alcohol consumption among those who quit smoking with e-cigarettes was 7.78 units/week, and among those who quit with NRT and no aid it was 7.12 and 5.55 units/week, respectively. The unadjusted analyses indicated that those who quit with e-cigarettes consumed a significantly higher number of units of alcohol each week than those who quit with no aid ( $B=2.22,95 \% \mathrm{Cl} 0.65$ to 3.79$)$, but there was no significant difference relative to those who quit with NRT. These results persisted after adjustment for sociodemographic, smoking, and drinking characteristics, with those who quit smoking with e-cigarettes consuming approximately 1.69 more units of alcohol each week than those who quit unaided $(B=1.69,95 \% \mathrm{Cl} 0.21$ to 3.17). However, when current use of e-cigarettes and NRT were adjusted for, this association was attenuated and was no longer statistically significant ( $B=1.56,95 \% \mathrm{Cl}-1.14$ to 4.27 ) (Table S2).

The prevalence of high-risk drinking was $43.3 \%$ among those who quit smoking with e-cigarettes, $32.2 \%$ among those who quit with NRT, and $36.8 \%$ among those who quit with no aid. The unadjusted analyses indicated that those who quit with e-cigarettes had higher odds of being high-risk drinkers than those who quit with $\mathrm{NRT}(\mathrm{OR}=1.61,95 \% \mathrm{Cl} 1.04$ to 2.49 ), but the difference between e-cigarettes and no aid did not reach statistical significance $(\mathrm{OR}=1.31,95 \% \mathrm{Cl} 0.99$ to 1.73$)$. These differences were attenuated and not statistically significant after adjustment for covariates (Table 2, Table S2). 
Among high-risk drinkers, the prevalence of attempts to cut down alcohol consumption was $22.3 \%$ among those who quit smoking with e-cigarettes, $18.9 \%$ among those who quit with NRT, and $27.7 \%$ among those who quit with no aid. Differences were not statistically significant in either unadjusted or adjusted models (Table 2, Table S2).

Bayes factors indicated the data provided moderate evidence of higher alcohol consumption among those who quit smoking with e-cigarettes than those who quit with no aid. There was moderate evidence against those who quit with e-cigarettes having a higher alcohol consumption than those who quit with NRT. Data were insensitive to detect meaningful differences in the prevalence of high-risk drinking or attempts to cut down alcohol consumption, but slightly favoured the null hypothesis (Table S3).

Sensitivity analyses excluding non-drinkers $(n=268)$ and those who used behavioural support in addition to e-cigarettes or NRT ( $n=12$ ) produced a very similar pattern of results (see Tables S4 and S5, respectively). There was no significant interaction between type of cessation aid used (e-cigarettes, NRT, no aid) and sex for any outcome (alcohol consumption $p=0.062$, high-risk drinking $p=0.456$, attempts to cut down alcohol consumption $p=0.454)$.

\section{Discussion}

Smokers who made a successful quit attempt with e-cigarettes reported significantly higher alcohol consumption than those who quit unaided, after adjustment for relevant sociodemographic, smoking, and drinking characteristics; a difference of approximately two units per week. This was explained in part by continued use of e-cigarettes after cessation, with no significant difference observed when current product use was adjusted for. Crucially, there was no difference in alcohol consumption between those who quit with e-cigarettes and those who quit with NRT. In unadjusted models, those who quit with e-cigarettes had higher odds of being classified as a high-risk drinker than those who quit with NRT or no aid, but these differences were largely explained by covariates. Among high-risk drinkers, we found no evidence of differences in attempts to cut down alcohol consumption by smoking cessation aid used.

Previous studies regarding associations between use of cessation aids and alcohol use have produced contradictory evidence, suggesting e-cigarette use is associated with increased alcohol consumption (Hershberger et al., 2016c, 2016b; Saddleson et al., 2015) and NRT use is associated with decreased 
consumption (Acheson et al., 2006; McKee et al., 2008; Young et al., 2005), but none to our knowledge has explicitly compared e-cigarettes with NRT. Our finding that smokers who had quit with e-cigarettes reported higher alcohol consumption than those who used no aid is consistent with studies reporting an association between e-cigarette use and higher alcohol consumption (Hershberger et al., 2016c, 2016b; Saddleson et al., 2015). However, this did not appear to be specific to e-cigarette use, with smokers who had quit with NRT reporting similar levels of consumption; a finding that appears to be at odds with evidence linking use of NRT with a reduction in alcohol consumption in heavy-drinking smokers (Acheson et al., 2006; McKee et al., 2008; Young et al., 2005) and attenuated alcohol response and craving (Udo et al., 2013). With no data available on alcohol consumption prior to quitting smoking, it is not clear whether any changes in drinking patterns were masked by baseline differences in drinking behaviour between those who chose to use ecigarettes, NRT, or no aid to support their quit attempt.

The higher prevalence of high-risk drinking in those who quit smoking with e-cigarettes compared with those who quit with NRT or no aid is consistent with research linking e-cigarette use with a higher rate of binge drinking (Saddleson et al., 2015). In contrast to mean alcohol consumption, a difference was observed between those who quit with e-cigarettes and those who quit with NRT. While these differences became non-significant after adjustment for sociodemographic characteristics, time since quitting, level of cigarette addiction, and indicators of past-year problematic drinking, point estimates were in the same direction and Bayes factors indicated that the data were insensitive, so we cannot conclusively rule out e-cigarette users being more likely to engage in high-risk drinking.

The prevalence of attempts to cut down alcohol consumption in high-risk drinkers was highest in those who had quit smoking unaided and lowest in those who quit using NRT, with those who quit using e-cigarettes in between. However, differences were not statistically significant with or without adjustment for covariates. While the data were insensitive, meaning we cannot rule out heavy-drinking smokers who quit with ecigarettes being less likely to try to cut down their alcohol consumption, they favoured the null hypothesis for the comparison with those who quit with NRT. This suggests that any association with attempts to cut down is not unique to e-cigarettes.

There are several potential explanations for smokers who quit with e-cigarettes having similar consumption to those who quit with NRT but higher consumption than those who quit unaided. Smokers who use ecigarettes and NRT to support their quit attempt may feel more able to drink alcohol without risking relapse because the alternative nicotine provides a method of relieving nicotine cravings. With participants who had 
quit using either e-cigarettes or NRT substantially more likely to report using either one of these products at the time of the survey (i.e. past the point of cessation) than those who quit with no aid, the continued use of these products may offer a safety blanket to ex-smokers worried about relapsing while under the influence of alcohol. Given the similarity with people who use NRT, the argument seems unlikely that the similarity between e-cigarettes and combustible cigarettes prevents the uncoupling of conditioned stimulusresponse effects between smoking and alcohol (Rohsenow et al., 1997). Alternatively, higher alcohol consumption may predate the initiation of e-cigarette and NRT use and is driven by unmeasured confounding. It is possible that people with higher levels of alcohol consumption are either more likely to choose e-cigarettes or NRT to support their quit attempt, or more successful in quitting with these products.

Regardless of the reasons underlying the association between use of e-cigarettes for smoking cessation and higher alcohol consumption, the present results taken together with previous findings (Hershberger et al., 2016a, 2016c, 2016b; Saddleson et al., 2015) suggest that including advice to reduce alcohol consumption within behavioural support might be useful for smokers who quit using alternative nicotine (Friend and Pagano, 2005; Gulliver et al., 2006; Kahler et al., 2010). Smokers are already routinely advised to restrict their alcohol consumption during an attempt to stop as part of relapse prevention. Further advice may warn against overconfidence that alternative nicotine would be sufficient to prevent relapse. However, given the modest size of the association (a difference of two units of alcohol per week; smaller than is typically seen in brief interventions to reduce alcohol consumption (Kaner et al., 2007)), concerns about associations with alcohol consumption should not discourage health professionals from recommending e-cigarettes to smokers as a cessation aid.

This study had several limitations. Data were cross-sectional, so we were unable to establish the direction of causation for observed association between use of e-cigarettes for smoking cessation and alcohol consumption. While we controlled for two indicators of past-year problematic drinking (injury to self or others and concern expressed by others) in an effort to capture past drinking behaviour, no information was available on level of alcohol consumption prior to quitting smoking. Further research using a longitudinal design is required to provide insight into the nature of this relationship. The groups were self-selected and differed on a number of sociodemographic and smoking characteristics, introducing scope for bias. If the group most likely to use e-cigarettes for smoking cessation is a specific subgroup of the population, it is difficult to disentangle the probable impact of e-cigarette use on alcohol consumption from selection effects. Experimental studies using a randomised design are needed. Another limitation was the reliance on self-reported alcohol data. Although the AUDIT has been widely validated (Reinert and Allen, 2007), there is 
a risk of recall bias, participants underestimating or failing to report their drinking, and responses being influenced by interviewer effects. However, it seems unlikely that such biases would have differed between study groups, so this should not have affected our findings. We made no exclusions on the basis of extent of alcohol consumption, so both participants who were teetotal and those who were very heavy drinkers were included, which may have influenced our results. For some outcomes (prevalence of high-risk drinking and attempts to cut down alcohol consumption), Bayes factors indicated that data were insensitive to detect differences. Given these limitations, replication of these findings with a larger sample is necessary to provide evidence for, or rule out, associations between use of e-cigarettes for smoking cessation and highrisk drinking or attempts to cut down among high-risk drinkers. Additionally, while a number of sociodemographic differences between those who quit smoking with e-cigarettes, NRT, or no aid were identified in the present sample and adjusted for in our analyses, we did not examine moderation effects. Further research could investigate whether associations between use of e-cigarettes for smoking cessation and alcohol use are moderated by sociodemographic characteristics, pre-cessation smoking or drinking behaviour, or frequency of e-cigarette use.

\subsection{Conclusions}

Recent ex-smokers who used e-cigarettes to help them quit smoking consumed around two more units of alcohol each week than those who quit unaided, but their alcohol consumption was similar to that of those who quit with NRT. Data on differences in high-risk drinking and attempts to cut down alcohol consumption among high-risk drinkers were inconclusive. 


\section{References}

Acheson, A., Mahler, S.V., Chi, H., de Wit, H., 2006. Differential effects of nicotine on alcohol consumption in men and women. Psychopharmacology (Berl.) 186, 54.

Babor, T.F., Higgins-Biddle, J.C., Saunders, J.B., Monteiro, M.G., Organization, W.H., 2001. AUDIT: the alcohol use disorders identification test: guidelines for use in primary health care.

Beard, E., Brown, J., West, R., Acton, C., Brennan, A., Drummond, C., Hickman, M., Holmes, J., Kaner, E., Lock, K., Walmsley, M., Michie, S., 2015. Protocol for a national monthly survey of alcohol use in England with 6-month follow-up: 'The Alcohol Toolkit Study.' BMC Public Health 15, 230. https://doi.org/10.1186/s12889-015-1542-7

Beard, E., Brown, J., West, R., Kaner, E., Meier, P., Michie, S., 2019. Associations between socioeconomic factors and alcohol consumption: A population survey of adults in England. PLOS ONE 14, e0209442. https://doi.org/10.1371/journal.pone.0209442

Beard, E., West, R., Michie, S., Brown, J., 2017. Association between smoking and alcohol-related behaviours: a time-series analysis of population trends in England. Addict. Abingdon Engl. 112, 1832-1841. https://doi.org/10.1111/add.13887

Beard, E., West, R., Michie, S., Brown, J., 2016. Association between electronic cigarette use and changes in quit attempts, success of quit attempts, use of smoking cessation pharmacotherapy, and use of stop smoking services in England: time series analysis of population trends. BMJ 354, i4645. https://doi.org/10.1136/bmj.i4645

Biener, L., Hargraves, J.L., 2015. A Longitudinal Study of Electronic Cigarette Use Among a Population-Based Sample of Adult Smokers: Association With Smoking Cessation and Motivation to Quit. Nicotine Tob. Res. 17, 127-133. https://doi.org/10.1093/ntr/ntu200

Bradley, K.A., DeBenedetti, A.F., Volk, R.J., Williams, E.C., Frank, D., Kivlahan, D.R., 2007. AUDIT-C as a brief screen for alcohol misuse in primary care. Alcohol. Clin. Exp. Res. 31, 1208-1217. https://doi.org/10.1111/j.1530-0277.2007.00403.x

Brown, J., West, R., Beard, E., Brennan, A., Drummond, C., Gillespie, D., Hickman, M., Holmes, J., Kaner, E., Michie, S., 2016. Are recent attempts to quit smoking associated with reduced drinking in England? A cross-sectional population survey. BMC Public Health 16, 535. https://doi.org/10.1186/s12889-016-3223-6

Brown, J., West, R., Beard, E., Michie, S., Shahab, L., McNeill, A., 2014. Prevalence and characteristics of e-cigarette users in Great Britain: Findings from a general population survey of smokers. Addict. Behav. 39, 1120-1125. https://doi.org/10.1016/j.addbeh.2014.03.009

Caetano, R., Baruah, J., Chartier, K.G., 2011. Ten-Year Trends (1992 to 2002) in Sociodemographic Predictors and Indicators of Alcohol Abuse and Dependence Among Whites, Blacks, and Hispanics in the United States. Alcohol. Clin. Exp. Res. 35, 1458-1466. https://doi.org/10.1111/j.1530-0277.2011.01482.x

Dienes, Z., 2014. Using Bayes to get the most out of non-significant results. Front. Psychol. 5. https://doi.org/10.3389/fpsyg.2014.00781

Falk, D.E., Yi, H., Hiller-Sturmhöfel, S., 2006. An epidemiologic analysis of co-occurring alcohol and tobacco use and disorders: findings from the National Epidemiologic Survey on Alcohol and Related Conditions. Alcohol Res. Health J. Natl. Inst. Alcohol Abuse Alcohol. 29, 162171. 
Fidler, J.A., Shahab, L., West, O., Jarvis, M.J., McEwen, A., Stapleton, J.A., Vangeli, E., West, R., 2011a. "The smoking toolkit study": a national study of smoking and smoking cessation in England. BMC Public Health 11, 479. https://doi.org/10.1186/1471-2458-11-479

Fidler, J.A., Shahab, L., West, R., 2011b. Strength of urges to smoke as a measure of severity of cigarette dependence: comparison with the Fagerström Test for Nicotine Dependence and its components. Addict. Abingdon Engl. 106, 631-638. https://doi.org/10.1111/j.13600443.2010.03226.x

Filippidis, F.T., Laverty, A.A., Gerovasili, V., Vardavas, C.I., 2017. Two-year trends and predictors of e-cigarette use in 27 European Union member states. Tob. Control 26, 98-104. https://doi.org/10.1136/tobaccocontrol-2015-052771

Friedman, G.D., Tekawa, I., Klatsky, A.L., Sidney, S., Armstrong, M.A., 1991. Alcohol drinking and cigarette smoking: an exploration of the association in middle-aged men and women. Drug Alcohol Depend. 27, 283-290.

Friend, K.B., Pagano, M.E., 2005. Smoking Cessation and Alcohol Consumption in Individuals in Treatment for Alcohol Use Disorders. J. Addict. Dis. 24, 61-75.

Grant, B.F., Hasin, D.S., Chou, S.P., Stinson, F.S., Dawson, D.A., 2004. Nicotine dependence and psychiatric disorders in the united states: Results from the national epidemiologic survey on alcohol and relatedconditions. Arch. Gen. Psychiatry 61, 1107-1115.

Griswold, M.G., Fullman, N., Hawley, C., Arian, N., Zimsen, S.R.M., Tymeson, H.D., Venkateswaran, V., Tapp, A.D., Forouzanfar, M.H., Salama, J.S., Abate, K.H., Abate, D., Abay, S.M., Abbafati, C., Abdulkader, R.S., Abebe, Z., Aboyans, V., Abrar, M.M., Acharya, P., Adetokunboh, O.O., Adhikari, T.B., Adsuar, J.C., Afarideh, M., Agardh, E.E., Agarwal, G., Aghayan, S.A., Agrawal, S., Ahmed, M.B., Akibu, M., Akinyemiju, T., Akseer, N., Asfoor, D.H.A., Al-Aly, Z., Alahdab, F., Alam, K., Albujeer, A., Alene, K.A., Ali, R., Ali, S.D., Alijanzadeh, M., Aljunid, S.M., Alkerwi, A., Allebeck, P., Alvis-Guzman, N., Amare, A.T., Aminde, L.N., Ammar, W., Amoako, Y.A., Amul, G.G.H., Andrei, C.L., Angus, C., Ansha, M.G., Antonio, C.A.T., Aremu, O., Ärnlöv, J., Artaman, A., Aryal, K.K., Assadi, R., Ausloos, M., Avila-Burgos, L., Avokpaho, E.F., Awasthi, A., Ayele, H.T., Ayer, R., Ayuk, T.B., Azzopardi, P.S., Badali, H., Badawi, A., Banach, M., Barker-Collo, S.L., Barrero, L.H., Basaleem, H., Baye, E., Bazargan-Hejazi, S., Bedi, N., Béjot, Y., Belachew, A.B., Belay, S.A., Bennett, D.A., Bensenor, I.M., Bernabe, E., Bernstein, R.S., Beyene, A.S., Beyranvand, T., Bhaumik, S., Bhutta, Z.A., Biadgo, B., Bijani, A., Bililign, N., Birlik, S.M., Birungi, C., Bizuneh, H., Bjerregaard, P., Bjørge, T., Borges, G., Bosetti, C., Boufous, S., Bragazzi, N.L., Brenner, H., Butt, Z.A., Cahuana-Hurtado, L., Calabria, B., Campos-Nonato, I.R., Campuzano, J.C., Carreras, G., Carrero, J.J., Carvalho, F., Castañeda-Orjuela, C.A., Rivas, J.C., Catalá-López, F., Chang, J.-C., Charlson, F.J., Chattopadhyay, A., Chaturvedi, P., Chowdhury, R., Christopher, D.J., Chung, S.-C., Ciobanu, L.G., Claro, R.M., Conti, S., Cousin, E., Criqui, M.H., Dachew, B.A., Dargan, P.I., Daryani, A., Neves, J.D., Davletov, K., Castro, F.D., Courten, B.D., Neve, J.-W.D., Degenhardt, L., Demoz, G.T., Jarlais, D.C.D., Dey, S., Dhaliwal, R.S., Dharmaratne, S.D., Dhimal, M., Doku, D.T., Doyle, K.E., Dubey, M., Dubljanin, E., Duncan, B.B., Ebrahimi, H., Edessa, D., Zaki, M.E.S., Ermakov, S.P., Erskine, H.E., Esteghamati, A., Faramarzi, M., Farioli, A., Faro, A., Farvid, M.S., Farzadfar, F., Feigin, V.L., Felisbino-Mendes, M.S., Fernandes, E., Ferrari, A.J., Ferri, C.P., Fijabi, D.O., Filip, I., Finger, J.D., Fischer, F., Flaxman, A.D., Franklin, R.C., Futran, N.D., Gallus, S., Ganji, M., Gankpe, F.G., Gebregergs, G.B., Gebrehiwot, T.T., Geleijnse, J.M., Ghadimi, R., Ghandour, L.A., Ghimire, M., Gill, P.S., Ginawi, I.A., Giref, A.Z.Z., Gona, 
P.N., Gopalani, S.V., Gotay, C.C., Goulart, A.C., Greaves, F., Grosso, G., Guo, Y., Gupta, Rahul, Gupta, Rajeev, Gupta, V., Gutiérrez, R.A., Gvs, M., Hafezi-Nejad, N., Hagos, T.B., Hailu, G.B., Hamadeh, R.R., Hamidi, S., Hankey, G.J., Harb, H.L., Harikrishnan, S., Haro, J.M., Hassen, H.Y., Havmoeller, R., Hay, S.I., Heibati, B., Henok, A., Heredia-Pi, I., Hernández-Llanes, N.F., Herteliu, C., Hibstu, D.T.T., Hoogar, P., Horita, N., Hosgood, H.D., Hosseini, M., Hostiuc, M., Hu, G., Huang, H., Husseini, A., Idrisov, B., Ileanu, B.V., Ilesanmi, O.S., Irvani, S.S.N., Islam, S.M.S., Jackson, M.D., Jakovljevic, M., Jalu, M.T., Jayatilleke, A.U., Jha, R.P., Jonas, J.B., Jozwiak, J.J., Kabir, Z., Kadel, R., Kahsay, A., Kapil, U., Kasaeian, A., Kassa, T.D.D., Katikireddi, S.V., Kawakami, N., Kebede, S., Kefale, A.T., Keiyoro, P.N., Kengne, A.P., Khader, Y., Khafaie, M.A., Khalil, I.A., Khan, M.N., Khang, Y.-H., Khater, M.M., Khubchandani, J., Kim, C.-I., Kim, D., Kim, Y.J., Kimokoti, R.W., Kisa, A., Kivimäki, M., Kochhar, S., Kosen, S., Koul, P.A., Koyanagi, A., Krishan, K., Defo, B.K., Bicer, B.K., Kulkarni, V.S., Kumar, P., Lafranconi, A., Balaji, A.L., Lalloo, R., Lallukka, T., Lam, H., Lami, F.H., Lan, Q., Lang, J.J., Lansky, S., Larsson, A.O., Latifi, A., Leasher, J.L., Lee, P.H., Leigh, J., Leinsalu, M., Leung, J., Levi, M., Li, Y., Lim, L.-L., Linn, S., Liu, S., Lobato-Cordero, A., Lopez, A.D., Lorkowski, S., Lotufo, P.A., Macarayan, E.R.K., Machado, I.E., Madotto, F., Razek, H.M.A.E., Razek, M.M.A.E., Majdan, M., Majdzadeh, R., Majeed, A., Malekzadeh, R., Malta, D.C., Mapoma, C.C., Martinez-Raga, J., Maulik, P.K., Mazidi, M., Mckee, M., Mehta, V., Meier, T., Mekonen, T., Meles, K.G., Melese, A., Memiah, P.T.N., Mendoza, W., Mengistu, D.T., Mensah, G.A., Meretoja, T.J., Mezgebe, H.B., Miazgowski, T., Miller, T.R., Mini, G., Mirica, A., Mirrakhimov, E.M., Moazen, B., Mohammad, K.A., Mohammadifard, N., Mohammed, S., Monasta, L., Moraga, P., Morawska, L., Mousavi, S.M., Mukhopadhyay, S., Musa, K.I., Naheed, A., Naik, G., Najafi, F., Nangia, V., Nansseu, J.R., Nayak, M.S.D.P., Nejjari, C., Neupane, S., Neupane, S.P., Ngunjiri, J.W., Nguyen, C.T., Nguyen, L.H., Nguyen, T.H., Ningrum, D.N.A., Nirayo, Y.L., Noubiap, J.J., Ofori-Asenso, R., Ogbo, F.A., Oh, I.-H., Oladimeji, O., Olagunju, A.T., Olivares, P.R., Olusanya, B.O., Olusanya, J.O., Oommen, A.M., Oren, E., Orpana, H.M., Ortega-Altamirano, D.D.V., Ortiz, J.R., Ota, E., Owolabi, M.O., Oyekale, A.S., A, M.P., Pana, A., Park, E.-K., Parry, C.D.H., Parsian, H., Patle, A., Patton, G.C., Paudel, D., Petzold, M., Phillips, M.R., Pillay, J.D., Postma, M.J., Pourmalek, F., Prabhakaran, D., Qorbani, M., Radfar, A., Rafay, A., Rafiei, A., Rahim, F., RahimiMovaghar, A., Rahman, M., Rahman, M.A., Rai, R.K., Rajsic, S., Raju, S.B., Ram, U., Rana, S.M., Ranabhat, C.L., Rawaf, D.L., Rawaf, S., Reiner, R.C., Reis, C., Renzaho, A.M.N., Rezai, M.S., Roever, L., Ronfani, L., Room, R., Roshandel, G., Rostami, A., Roth, G.A., Roy, A., Sabde, Y.D., Saddik, B., Safiri, S., Sahebkar, A., Salama, J.S., Saleem, Z., Salomon, J.A., Salvi, S.S., Sanabria, J., Sanchez-Niño, M.D., Santomauro, D.F., Santos, I.S., Milicevic, M.M.M.S., Sarker, A.R., Sarmiento-Suárez, R., Sarrafzadegan, N., Sartorius, B., Satpathy, M., Sawhney, M., Saxena, S., Saylan, M., Schaub, M.P., Schmidt, M.I., Schneider, I.J.C., Schöttker, B., Schutte, A.E., Schwendicke, F., Sepanlou, S.G., Shaikh, M.A., Sharif, M., She, J., Sheikh, A., Shen, J., Shiferaw, M.S., Shigematsu, M., Shiri, R., Shishani, K., Shiue, I., Shukla, S.R., Sigfusdottir, I.D., Silva, D.A.S., Silva, N.T.D., Silveira, D.G.A., Sinha, D.N., Sitas, F., Filho, A.M.S., Soofi, M., Sorensen, R.J.D., Soriano, J.B., Sreeramareddy, C.T., Steckling, N., Stein, D.J., Sufiyan, M.B., Sur, P.J., Sykes, B.L., Tabarés-Seisdedos, R., Tabuchi, T., Tavakkoli, M., Tehrani-Banihashemi, A., Tekle, M.G., Thapa, S., Thomas, N., Topor-Madry, R., Topouzis, F., Tran, B.X., Troeger, C.E., Truelsen, T.C., Tsilimparis, N., Tyrovolas, S., Ukwaja, K.N., Ullah, I., Uthman, O.A., Valdez, P.R., 
Boven, J.F.M.V., Vasankari, T.J., Venketasubramanian, N., Violante, F.S., Vladimirov, S.K., Vlassov, V., Vollset, S.E., Vos, T., Wagnew, F.W.S., Waheed, Y., Wang, Y.-P., Weiderpass, E., Weldegebreal, F., Weldegwergs, K.G., Werdecker, A., Westerman, R., Whiteford, H.A., Widecka, J., Wijeratne, T., Wyper, G.M.A., Xu, G., Yamada, T., Yano, Y., Ye, P., Yimer, E.M., Yip, P., Yirsaw, B.D., Yisma, E., Yonemoto, N., Yoon, S.-J., Yotebieng, M., Younis, M.Z., Zachariah, G., Zaidi, Z., Zamani, M., Zhang, X., Zodpey, S., Mokdad, A.H., Naghavi, M., Murray, C.J.L., Gakidou, E., 2018. Alcohol use and burden for 195 countries and territories, 1990-2016: a systematic analysis for the Global Burden of Disease Study 2016. The Lancet 392, 1015-1035. https://doi.org/10.1016/S0140-6736(18)31310-2

Gulliver, S.B., Kamholz, B.W., Helstrom, A.W., 2006. Smoking cessation and alcohol abstinence: What do the data tell us? Alcohol Res. Health 29, 208-212.

Hacking, J.M., Muller, S., Buchan, I.E., 2011. Trends in mortality from 1965 to 2008 across the English north-south divide: comparative observational study. Bmj 342, d508.

Hajek, P., Phillips-Waller, A., Przulj, D., Pesola, F., Myers Smith, K., Bisal, N., Li, J., Parrott, S., Sasieni, P., Dawkins, L., Ross, L., Goniewicz, M., Wu, Q., McRobbie, H.J., 2019. A Randomized Trial of E-Cigarettes versus Nicotine-Replacement Therapy. N. Engl. J. Med. 380, 629-637. https://doi.org/10.1056/NEJMoa1808779

Hartmann-Boyce, J., Begh, R., Aveyard, P., 2018. Electronic cigarettes for smoking cessation. BMJ 360, j5543. https://doi.org/10.1136/bmj.j5543

Hartmann-Boyce, J., McRobbie, H., Bullen, C., Begh, R., Stead, L.F., Hajek, P., 2016. Electronic cigarettes for smoking cessation. Cochrane Database Syst. Rev. 9, CD010216. https://doi.org/10.1002/14651858.CD010216.pub3

Hershberger, A.R., Karyadi, K.A., Cyders, M.A., 2016a. Prohibition of e-cigarettes in the US: Are prohibitions where alcohol is consumed related to lower alcohol consumption? J. Public Health Policy 37, 483-499. https://doi.org/10.1057/s41271-016-0033-0

Hershberger, A.R., Karyadi, K.A., VanderVeen, J.D., Cyders, M.A., 2016b. Combined expectancies of alcohol and e-cigarette use relate to higher alcohol use. Addict. Behav. 52, 13-21. https://doi.org/10.1016/j.addbeh.2015.08.005

Hershberger, A.R., VanderVeen, J.D., Karyadi, K.A., Cyders, M.A., 2016c. Transitioning from cigarettes to electronic cigarettes increases alcohol consumption. Subst. Use Misuse 51, 1838-1845. https://doi.org/10.1080/10826084.2016.1197940

Jackson, S.E., Kotz, D., West, R., Brown, J., 2019. Reply to "Smoke free, but addicted to nicotine." Addiction.

Jeffreys, H., 1961. The Theory of Probability. Clarendon Press, Oxford.

Kahler, C.W., Spillane, N.S., Metrik, J., 2010. Alcohol use and initial smoking lapses among heavy drinkers in smoking cessation treatment. Nicotine Tob. Res. 12, 781-785. https://doi.org/10.1093/ntr/ntq083

Kalman, D., Morissette, S.B., George, T.P., 2005. Co-morbidity of smoking in patients with psychiatric and substance use disorders. Am. J. Addict. 14, 106-123. https://doi.org/10.1080/10550490590924728

Kaner, E.F.S., Beyer, F., Dickinson, H.O., Pienaar, E., Campbell, F., Schlesinger, C., Heather, N., Saunders, J., Burnand, B., 2007. Effectiveness of brief alcohol interventions in primary care populations. Cochrane Database Syst. Rev. CD004148. https://doi.org/10.1002/14651858.CD004148.pub3 
Kessler, R.C., Chiu, W.T., Demler, O., Merikangas, K.R., Walters, E.E., 2005. Prevalence, severity, and comorbidity of 12-month DSM-IV disorders in the National Comorbidity Survey Replication. Arch. Gen. Psychiatry 62, 617-627. https://doi.org/10.1001/archpsyc.62.6.617

Lasser, K., Boyd, J.W., Woolhandler, S., Himmelstein, D.U., McCormick, D., Bor, D.H., 2000. Smoking and mental illness: A population-based prevalence study. JAMA 284, 2606-2610.

Levy, D.T., Yuan, Z., Li, Y., 2017. The Prevalence and Characteristics of E-Cigarette Users in the U.S. Int. J. Environ. Res. Public. Health 14. https://doi.org/10.3390/ijerph14101200

Lima, C.T., Freire, A.C.C., Silva, A.P.B., Teixeira, R.M., Farrell, M., Prince, M., 2005. CONCURRENT AND CONSTRUCT VALIDITY OF THE AUDIT IN AN URBAN BRAZILIAN SAMPLE. Alcohol Alcohol 40, 584-589. https://doi.org/10.1093/alcalc/agh202

McKee, S.A., Falba, T., O’Malley, S.S., Sindelar, J., O’Connor, P.G., 2007. Smoking status as a clinical indicator for alcohol misuse in US adults. Arch. Intern. Med. 167, 716-721.

McKee, S.A., O’Malley, S.S., Shi, J., Mase, T., Krishnan-Sarin, S., 2008. Effect of transdermal nicotine replacement on alcohol responses and alcohol self-administration.

Psychopharmacology (Berl.) 196, 189-200.

McMillen, R.C., Gottlieb, M.A., Shaefer, R.M.W., Winickoff, J.P., Klein, J.D., 2015. Trends in Electronic Cigarette Use Among U.S. Adults: Use is Increasing in Both Smokers and Nonsmokers. Nicotine Tob. Res. 17, 1195-1202. https://doi.org/10.1093/ntr/ntu213

McNeill, A., Brose, L.S., Calder, R., Bauld, L., Robson, D., 2018. Evidence review of e-cigarettes and heated tobacco products 2018. A report commissioned by Public Health England.

Noble, N., Paul, C., Turon, H., Oldmeadow, C., 2015. Which modifiable health risk behaviours are related? A systematic review of the clustering of Smoking, Nutrition, Alcohol and Physical activity ('SNAP') health risk factors. Prev. Med. 81, 16-41. https://doi.org/10.1016/j.ypmed.2015.07.003

O’Malley, P.M., Johnston, L.D., 2002. Epidemiology of alcohol and other drug use among American college students. J. Stud. Alcohol. Suppl. 23-39. https://doi.org/10.15288/jsas.2002.s14.23

Patel, D., Davis, K.C., Cox, S., Bradfield, B., King, B.A., Shafer, P., Caraballo, R., Bunnell, R., 2016. Reasons for current E-cigarette use among US adults. Prev. Med. 93, 14-20.

Reinert, D.F., Allen, J.P., 2007. The Alcohol Use Disorders Identification Test: An Update of Research Findings. Alcohol. Clin. Exp. Res. 31, 185-199. https://doi.org/10.1111/j.15300277.2006.00295.x

Reitsma, M.B., Fullman, N., Ng, M., Salama, J.S., Abajobir, A., Abate, K.H., Abbafati, C., Abera, S.F., Abraham, B., Abyu, G.Y., Adebiyi, A.O., Al-Aly, Z., Aleman, A.V., Ali, R., Al Alkerwi, A., Allebeck, P., Al-Raddadi, R.M., Amare, A.T., Amberbir, A., Ammar, W., Amrock, S.M., Antonio, C.A.T., Asayesh, H., Atnafu, N.T., Azzopardi, P., Banerjee, A., Barac, A., Barrientos-Gutierrez, T., Basto-Abreu, A.C., Bazargan-Hejazi, S., Bedi, N., Bell, B., Bello, A.K., Bensenor, I.M., Beyene, A.S., Bhala, N., Biryukov, S., Bolt, K., Brenner, H., Butt, Z., Cavalleri, F., Cercy, K., Chen, H., Christopher, D.J., Ciobanu, L.G., Colistro, V., Colomar, M., Cornaby, L., Dai, X., Damtew, S.A., Dandona, L., Dandona, R., Dansereau, E., Davletov, K., Dayama, A., Degfie, T.T., Deribew, A., Dharmaratne, S.D., Dimtsu, B.D., Doyle, K.E., Endries, A.Y., Ermakov, S.P., Estep, K., Faraon, E.J.A., Farzadfar, F., Feigin, V.L., Feigl, A.B., Fischer, F., Friedman, J., G/hiwot, T.T., Gall, S.L., Gao, W., Gillum, R.F., Gold, A.L., Gopalani, S.V., Gotay, C.C., Gupta, Rahul, Gupta, Rajeev, Gupta, V., Hamadeh, R.R., Hankey, G., Harb, H.L., Hay, S.I., Horino, M., Horita, N., Hosgood, H.D., Husseini, 
A., Ileanu, B.V., Islami, F., Jiang, G., Jiang, Y., Jonas, J.B., Kabir, Z., Kamal, R., Kasaeian, A., Kesavachandran, C.N., Khader, Y.S., Khalil, I., Khang, Y.-H., Khera, S., Khubchandani, J., Kim, D., Kim, Y.J., Kimokoti, R.W., Kinfu, Y., Knibbs, L.D., Kokubo, Y., Kolte, D., Kopec, J., Kosen, S., Kotsakis, G.A., Koul, P.A., Koyanagi, A., Krohn, K.J., Krueger, H., Defo, B.K., Bicer, B.K., Kulkarni, C., Kumar, G.A., Leasher, J.L., Lee, A., Leinsalu, M., Li, T., Linn, S., Liu, P., Liu, S., Lo, L.-T., Lopez, A.D., Ma, S., El Razek, H.M.A., Majeed, A., Malekzadeh, R., Malta, D.C., Manamo, W.A., Martinez-Raga, J., Mekonnen, A.B., Mendoza, W., Miller, T.R., Mohammad, K.A., Morawska, L., Musa, K.I., Nagel, G., Neupane, S.P., Nguyen, Q., Nguyen, G., Oh, I.-H., Oyekale, A.S., Pa, M., Pana, A., Park, E.K., Patil, S.T., Patton, G.C., Pedro, J., Qorbani, M., Rafay, A., Rahman, M., Rai, R.K., Ram, U., Ranabhat, C.L., Refaat, A.H., Reinig, N., Roba, H.S., Rodriguez, A., Roman, Y., Roth, G., Roy, A., Sagar, R., Salomon, J.A., Sanabria, J., de Souza Santos, I., Sartorius, B., Satpathy, M., Sawhney, M., Sawyer, S., Saylan, M., Schaub, M.P., Schluger, N., Schutte, A.E., Sepanlou, S.G., Serdar, B., Shaikh, M.A., She, J., Shin, M.-J., Shiri, R., Shishani, K., Shiue, I., Sigfusdottir, I.D., Silverberg, J.I., Singh, J., Singh, V., Slepak, E.L., Soneji, S., Soriano, J.B., Soshnikov, S., Sreeramareddy, C.T., Stein, D.J., Stranges, S., Subart, M.L., Swaminathan, S., Szoeke, C.E.I., Tefera, W.M., Topor-Madry, R., Tran, B., Tsilimparis, N., Tymeson, H., Ukwaja, K.N., Updike, R., Uthman, O.A., Violante, F.S., Vladimirov, S.K., Vlassov, V., Vollset, S.E., Vos, T., Weiderpass, E., Wen, C.-P., Werdecker, A., Wilson, S., Wubshet, M., Xiao, L., Yakob, B., Yano, Y., Ye, P., Yonemoto, N., Yoon, S.-J., Younis, M.Z., Yu, C., Zaidi, Z., El Sayed Zaki, M., Zhang, A.L., Zipkin, B., Murray, C.J.L., Forouzanfar, M.H., Gakidou, E., 2017. Smoking prevalence and attributable disease burden in 195 countries and territories, 1990-2015: a systematic analysis from the Global Burden of Disease Study 2015. The Lancet 389, 1885-1906. https://doi.org/10.1016/S01406736(17)30819-X

Rohsenow, D.J., Monti, P.M., Colby, S.M., Gulliver, S.B., Sirota, A.D., Niaura, R.S., Abrams, D.B., 1997. Effects of Alcohol Cues on Smoking Urges and Topography among Alcoholic Men. Alcohol. Clin. Exp. Res. 21, 101-107. https://doi.org/10.1111/j.1530-0277.1997.tb03735.x

Rutten, L.J.F., Blake, K.D., Agunwamba, A.A., Grana, R.A., Wilson, P.M., Ebbert, J.O., Okamoto, J., Leischow, S.J., 2015. Use of E-Cigarettes Among Current Smokers: Associations Among Reasons for Use, Quit Intentions, and Current Tobacco Use. Nicotine Tob. Res. 17, 12281234. https://doi.org/10.1093/ntr/ntv003

Saddleson, M.L., Kozlowski, L.T., Giovino, G.A., Hawk, L.W., Murphy, J.M., MacLean, M.G., Goniewicz, M.L., Homish, G.G., Wrotniak, B.H., Mahoney, M.C., 2015. Risky behaviors, ecigarette use and susceptibility of use among college students. Drug Alcohol Depend. 149, 25-30. https://doi.org/10.1016/j.drugalcdep.2015.01.001

Schoenborn, C.A., Gindi, R.M., 2015. Electronic cigarette use among adults: United States, 2014. US Department of Health and Human Services, Centers for Disease Control and Prevention, National Center for Health Statistics Atlanta, GA.

Shi, Y., Pierce, J.P., White, M., Vijayaraghavan, M., Compton, W., Conway, K., Hartman, A.M., Messer, K., 2016. E-cigarette use and smoking reduction or cessation in the 2010/2011 TUSCPS longitudinal cohort. BMC Public Health 16, 1105. https://doi.org/10.1186/s12889-0163770-X

Simonavicius, E., McNeill, A., Arnott, D., Brose, L.S., 2017. What factors are associated with current smokers using or stopping e-cigarette use? Drug Alcohol Depend. 173, 139-143. https://doi.org/10.1016/j.drugalcdep.2017.01.002 
Udo, T., Harrison, E.L.R., Shi, J., Tetrault, J., McKee, S.A., 2013. A Preliminary Study on the Effect of Combined Nicotine Replacement Therapy on Alcohol Responses and Alcohol Selfadministration. Am. J. Addict. Am. Acad. Psychiatr. Alcohol. Addict. 22, 590-597. https://doi.org/10.1111/j.1521-0391.2013.12014.x

Vardavas, C.I., Filippidis, F.T., Agaku, I.T., 2015. Determinants and prevalence of e-cigarette use throughout the European Union: a secondary analysis of 26566 youth and adults from 27 Countries. Tob. Control 24, 442-448. https://doi.org/10.1136/tobaccocontrol-2013-051394

West, R., Brown, J., Shahab, L., 2017. Written evidence submitted by University College London, Tobacco and Alcohol Research Group (UTARG) (ECG0047) [WWW Document]. URL http://data.parliament.uk/writtenevidence/committeeevidence.svc/evidencedocument/science -and-technology-committee/ecigarettes/written/75276.html (accessed 10.11.18).

West, R., Proudfoot, H., Beard, E., Brown, J., 2019. Electronic cigarettes in England - latest trends. Smoking in England.

Young, E.M., Mahler, S., Chi, H., de Wit, H., 2005. Mecamylamine and ethanol preference in healthy volunteers. Alcohol. Clin. Exp. Res. 29, 58-65. 


\section{Tables}

Table 1. Sample characteristics, overall and by quitting aid

\begin{tabular}{|c|c|c|c|c|c|}
\hline & $\begin{array}{c}\text { Whole sample } \\
(n=961)\end{array}$ & $\begin{array}{c}\text { E-cigarettes } \\
(n=425)\end{array}$ & $\begin{array}{c}\text { NRT } \\
(n=116)\end{array}$ & $\begin{array}{l}\text { No aid } \\
(n=421)\end{array}$ & $P^{1}$ \\
\hline \multicolumn{6}{|l|}{ Age (years), \% (n) } \\
\hline $16-24$ & $18.9(181)$ & $17.6(75)^{\mathrm{a}}$ & $8.7(10)^{a, b}$ & $23.0(97)^{\mathrm{b}}$ & 0.004 \\
\hline $25-34$ & $24.6(236)$ & $24.9(106)$ & $26.1(30)$ & $23.8(100)$ & - \\
\hline $35-44$ & $17.4(167)$ & $19.5(83)^{\mathrm{a}}$ & $21.7(25)^{b}$ & $14.0(59)^{a, b}$ & - \\
\hline $45-54$ & $16.2(156)$ & $18.6(79)^{a}$ & $17.4(20)$ & $13.5(57)^{a}$ & - \\
\hline $55-64$ & $12.5(120)$ & $11.8(50)$ & $13.9(16)$ & $12.8(54)$ & - \\
\hline $65+$ & $10.4(100)$ & $7.5(32)^{a}$ & $12.2(14)$ & $12.8(54)^{a}$ & - \\
\hline Female, \% (n) & $47.3(455)$ & $41.9(178)^{a, b}$ & $53.0(61)^{b}$ & $51.3(216)^{a}$ & 0.030 \\
\hline White ethnicity, \% (n) & $90.0(862)$ & $94.1(399)^{a}$ & $89.6(103)$ & $85.9(360)^{a}$ & $<0.001$ \\
\hline Social grade C2DE, \% (n) & 49.5 (476) & $52.9(225)$ & $44.3(51)$ & $47.5(200)$ & 0.142 \\
\hline Live in the North, $\%(n)$ & $53.2(511)$ & $57.3(243)$ & $513(59)$ & $49.6(209)$ & 0.075 \\
\hline No post-16 qualifications, $\%(n)$ & $35.1(337)$ & $37.4(159)$ & $40.9(47)$ & $31.1(131)$ & 0.060 \\
\hline \multicolumn{6}{|l|}{ Time since quit, $\%(n)$} \\
\hline$<1$ month & $22.6(217)$ & $20.8(88)$ & $32.2(37)$ & $21.9(92)$ & 0.073 \\
\hline 1-6 months & $37.7(362)$ & $39.9(169)$ & $35.7(41)$ & $36.1(152)$ & - \\
\hline$>6$ months & $39.7(381)$ & $39.4(167)$ & $32.2(37)$ & $42.0(177)$ & - \\
\hline $\begin{array}{l}\text { Strength of urges to smoke (0-5), } \\
\text { mean (SD) }\end{array}$ & $0.88(1.21)$ & $0.99(1.22)^{\mathrm{a}}$ & $1.05(1.28)^{\mathrm{b}}$ & $0.71(1.18)^{a, b}$ & 0.001 \\
\hline \multicolumn{6}{|l|}{$\begin{array}{l}\text { Injury to self or others from } \\
\text { drinking, } \%(n)\end{array}$} \\
\hline No & $85.1(817)$ & 84.5 (359) & $87.0(100)$ & $85.2(358)$ & 0.949 \\
\hline Yes but not in last year & $12.2(117)$ & $12.7(54)$ & $11.3(13)$ & $11.9(50)$ & - \\
\hline Yes during the last year & $2.7(26)$ & $2.8(12)$ & $1.7(2)$ & $2.9(12)$ & - \\
\hline \multicolumn{6}{|l|}{$\begin{array}{l}\text { Concern about drinking } \\
\text { expressed by others, \% }(n)\end{array}$} \\
\hline No & $92.0(883)$ & $91.3(388)$ & $93.9(108)$ & $92.1(387)$ & 0.320 \\
\hline Yes but not in last year & $5.3(51)$ & $5.9(25)$ & $6.1(7)$ & 4.5 (19) & - \\
\hline Yes during the last year & $2.7(26)$ & $2.8(12)$ & $0(0)$ & $3.3(14)$ & - \\
\hline Currently using e-cigarettes, $\%(n)$ & $43.0(413)$ & $89.6(381)^{a, b}$ & $14.8(17)^{\mathrm{a}, \mathrm{c}}$ & $3.6(15)^{b, c}$ & $<0.001$ \\
\hline Currently using NRT, $\%(n)$ & $13.1(126)$ & $8.2(3)^{a, b}$ & $67.0(77)^{\mathrm{a}, \mathrm{c}}$ & $3.3(14)^{b, c}$ & $<0.001$ \\
\hline \multicolumn{6}{|l|}{ Survey year, \% (n) } \\
\hline 2014 & $19.7(189)$ & $19.5(83)$ & $19.1(22)$ & $20.0(84)$ & 0.192 \\
\hline 2015 & $20.4(196)$ & $20.5(87)$ & $24.3(28)$ & $19.2(81)$ & - \\
\hline 2016 & $20.1(193)$ & $22.4(95)$ & $15.7(18)$ & $19.0(80)$ & - \\
\hline 2017 & $20.0(192)$ & $20.2(86)$ & $26.1(30)$ & $18.1(76)$ & - \\
\hline 2018 & $17.3(166)$ & $15.3(65)$ & $13.9(16)$ & $20.2(85)$ & - \\
\hline 2019 & $2.6(25)$ & $2.1(9)$ & $0.9(1)$ & $3.6(15)$ & - \\
\hline
\end{tabular}

NRT=nicotine replacement therapy.

${ }^{1} p$ value for the comparison between smokers who quit successfully using e-cigarettes, NRT, or no aid.

a,b,c Groups differed significantly from one another. 
Note: There was a small amount of missing data on ethnicity $(n=3)$, region $(n=1)$, time since quit $(n=1)$, injury to self or others from drinking $(n=6)$, and concern about drinking expressed by others $(n=1)$. Valid percentages are provided for these variables for ease of interpretation. 
Table 2. Associations between quitting aid and drinking behaviour

\begin{tabular}{|c|c|c|c|c|c|c|c|}
\hline & \multirow{2}{*}{ (1) e-cigarettes } & \multirow{2}{*}{ (2) NRT } & \multirow{2}{*}{ (3) no aid } & \multicolumn{2}{|c|}{ (1) versus (2) } & \multicolumn{2}{|c|}{ (1) versus (3) } \\
\hline & & & & $B / O R[95 \% \mathrm{Cl}]$ & $p$ & $\mathrm{~B} / \mathrm{OR}[95 \% \mathrm{Cl}]$ & $p$ \\
\hline \multicolumn{8}{|c|}{$\begin{array}{l}\text { Alcohol consumption, mean (SD) } \\
\text { number of units per week }\end{array}$} \\
\hline Unadjusted & $7.78(13.41)$ & $7.12(13.85)$ & $5.55(8.70)$ & $0.66[-1.75 ; 3.06]$ & 0.591 & $2.22[0.65 ; 3.79]$ & 0.006 \\
\hline Adjusted $^{1}$ & - & - & - & $-0.25[-2.48 ; 1.99]$ & 0.829 & $1.69[0.21 ; 3.17]$ & 0.025 \\
\hline \multicolumn{8}{|c|}{ High-risk drinking, \% (n) } \\
\hline Unadjusted & $43.3(184)$ & $32.2(37)$ & $36.8(155)$ & $1.61[1.04 ; 2.49]$ & 0.032 & $1.31[0.99 ; 1.73]$ & 0.055 \\
\hline Adjusted $^{1}$ & - & - & - & $1.35[0.84 ; 2.17]$ & 0.210 & $1.25[0.91 ; 1.71]$ & 0.170 \\
\hline \multicolumn{8}{|c|}{$\begin{array}{l}\text { Attempts to cut down alcohol } \\
\text { consumption }{ }^{2}, \%(n)\end{array}$} \\
\hline Unadjusted & $22.3(41)$ & $18.9(7)$ & $27.7(43)$ & $1.23[0.50 ; 3.00]$ & 0.651 & $0.75[0.46 ; 1.22]$ & 0.247 \\
\hline Adjusted $^{1}$ & - & - & - & $1.17[0.45 ; 3.02]$ & 0.753 & $0.69[0.40 ; 1.19]$ & 0.183 \\
\hline
\end{tabular}

